\title{
Adjuvant recombinant thrombomodulin therapy for hepatopathy induced by vincristine, actinomycin $D$, and cyclophosphamide in pediatric rhabdomyosarcoma: A case report
}

\author{
TETSUKO KOBAYASHI $^{1,2}$, MAIKO NOGUCHI ${ }^{1}$, HIDEKI NAKAYAMA ${ }^{1}$, REIJI FUKANO ${ }^{1,3}$ and SHOUICHI OHGA ${ }^{2}$ \\ ${ }^{1}$ Division of Pediatrics, National Hospital Organization Kyushu Cancer Center, Fukuoka 811-1395; \\ ${ }^{2}$ Department of Pediatrics, Kyushu University Hospital, Fukuoka 812-8582; \\ ${ }^{3}$ Department of Pediatrics, Yamaguchi University Graduate School of Medicine, Ube 775-8505, Japan
}

Received November 14, 2018; Accepted April 30, 2019

DOI: $10.3892 / \mathrm{mco} .2019 .1864$

\begin{abstract}
Hepatopathy induced by vincristine, actinomycin D and cyclophosphamide (VAC) is a potentially lethal complication of VAC chemotherapy for pediatric malignancy, which is managed by conventional anticoagulation and liver-supporting treatment alone. We report a case of VAC-induced hepatopathy with coagulopathy and severe inflammation. A 15-year-old male with rhabdomyosarcoma receiving adjuvant chemotherapy presented with refractory thrombocytopenia, followed by abdominal tenderness and non-neutropenic fever. Hepatic dysfunction and coagulopathy subsequently emerged with persistent fever. This condition indicated disseminated intravascular coagulation. A diagnosis of 'very severe' sinusoidal obstruction syndrome/veno-occlusive disease (SOS/VOD) was established in accordance with the European Society for Blood and Marrow Transplantation diagnostic criteria for hepatic SOS/VOD in children. Early administration of recombinant thrombomodulin (rTM) (380 U/kg/day) and prednisolone (1.8 $\mathrm{mg} / \mathrm{kg} /$ day) successfully controlled the condition. Serum concentrations of pro-inflammatory cytokines increased with hepatopathy development but immediately decreased after
\end{abstract}

Correspondence to: Dr Tetsuko Kobayashi, Department of Pediatrics, Kyushu University Hospital, 3-1-1 Maidashi, Higashi-ku, Fukuoka 812-8582, Japan

E-mail: tkobayashi2010@gmail.com

Abbreviations: VAC, vincristine, actinomycin D, and cyclophosphamide; SOS/VOD, sinusoidal obstruction syndrome/veno-occlusive disease; rTM, recombinant thrombomodulin; AST, aspartate transaminase; ALT, alanine aminotransferase; T-Bil, total bilirubin; CRP, C-reactive protein; DIC, disseminated intravascular coagulation; HLH, hemophagocytic lymphohistiocytosis; PSL, prednisolone; TNF- $\alpha$, tumor necrosis factor- $\alpha$; ND, non-detectable; IL-1 $\beta$, interleukin-1 $\beta$; IL-6, interleukin-6; HMGB1, high-mobility group box 1 protein

Key words: chemotherapy, VAC-induced hepatopathy, inflammation, SOS/VOD, DIC, HLH, rTM, pro-inflammatory cytokines drug initiation. rTM administration may be promising for the control of inflammatory VAC-induced hepatopathy.

\section{Introduction}

Hepatopathy induced by vincristine, actinomycin D, and cyclophosphamide (VAC) is a potentially lethal complication of VAC chemotherapy for pediatric malignancy, including rhabdomyosarcoma (RMS), empirically managed by conventional anticoagulation therapy and liver-supporting agents. VAC-induced hepatopathy is pathophysiologically similar to sinusoidal obstruction syndrome/veno-occlusive disease (SOS/VOD) in the transplant setting, in which the primary insult is injury to the sinusoidal endothelial cells triggered by anticancer drug toxicity and proinflammatory cytokine release (1). The incidence rate of VAC-induced hepatopathy in RMS has been reported to be $1.2-15.4 \%$ (2-4). More efficient management than the current empirical one is required to avoid threat to life and minimize delays and dose reduction in chemotherapy. Thrombomodulin is a thrombin receptor on the endothelial cell surface. Recombinant thrombomodulin (rTM) consists of the active extracellular domain of thrombomodulin, including the N-terminal lectin-like domain with unique anti-inflammatory properties $(5,6)$. In particular, rTM administration exerts beneficial effects on the control of transplantation-associated thrombotic microangiopathy and SOS/VOD resulting from endothelial damage, coagulability, and exaggerated cytokine production (7). Nevertheless, the effect of rTM in VAC-induced hepatopathy remains unknown owing to the absence of reports.

We presented here a pediatric case of VAC-induced hepatopathy associated with coagulopathy and inflammation that was successfully controlled by the administration of rTM and conventional dose of prednisolone. The pathogenesis and management of VAC-induced hepatopathy with inflammatory cytokine profile were discussed in concert with the treatment response and literature review. Consent for publication of the case report was obtained from the patient and his mother. 


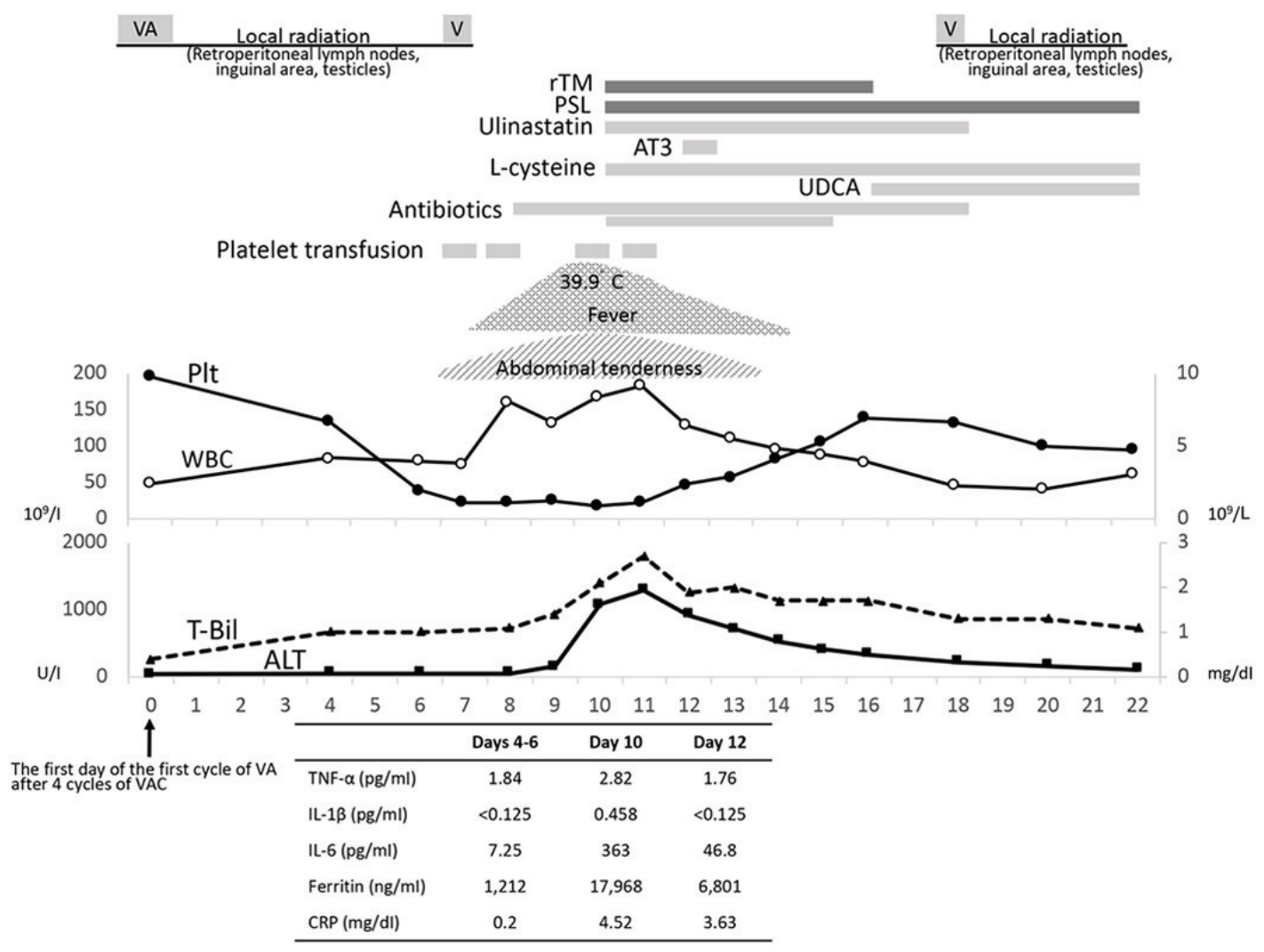

Figure 1. Treatment course and cytokine levels of the patient. AC, actinomycin D and cyclophosphamide; VA, vincristine and actinomycin D; V, vincristine; Plt, platelet; WBC, white blood cell; AST, aspartate transaminase; ALT, alanine transaminase; T-Bil, total bilirubin; CRP, C-reactive protein; TNF $\alpha$, tumor necrosis factor- $\alpha$; IL-1 $\beta$, interleukin-1 $\beta$; IL-6, interleukin-6; rTM, recombinant thrombomodulin; PSL, prednisolone; AT3, antithrombin III; UDCA, ursodeoxycholic acid.

\section{Case report}

Fig. 1 shows the timeline. A-15-year-old male with paratesticular RMS exhibiting no evidence of metastasis to other organs, including the liver, received adjuvant chemotherapy comprising four cycles of VAC (total cumulative dose of cyclophosphamide, $4.8 \mathrm{~g} / \mathrm{m}^{2}$ ) followed by four cycles of vincristine and actinomycin D with a total duration of 22 weeks with or without local radiation therapy (8). He had no personal and family history of injury or illness. During the 13th week of schedule for adjuvant chemotherapy from which the first cycle of vincristine and actinomycin D started after four cycles of VAC, he presented with refractory thrombocytopenia, along with subsequent abdominal tenderness and non-neutropenic fever. He was treated empirically with broad-spectrum intravenous antibiotics (cefepime) and continuously with platelet transfusion.

At day 3 of the 14th week (at 10 days after administration of vincristine and actinomycin $\mathrm{D}$ or at 2 days after administration of vincristine alone), full-blown hepatic dysfunction and coagulopathy were noted, along with persistent fever up to $39.6^{\circ} \mathrm{C}$ (leukocyte count, $8.37 \times 10^{9} / 1$; hemoglobin, $8.1 \mathrm{~g} / \mathrm{dl}$; platelet count, 18×10 $/ 1$; fibrinogen, $305 \mathrm{mg} / \mathrm{dl}$; prothrombin time-international normalized ratio, 1.82; antithrombin III, 73\%; fibrin/fibrinogen degradation products, $20.18 \mu \mathrm{g} / \mathrm{ml}$; aspartate transaminase [AST], $1961 \mathrm{U} / \mathrm{l}$; alanine aminotransferase [ALT], $1084 \mathrm{U} / 1$; total bilirubin [T-Bil], $2.1 \mathrm{mg} / \mathrm{dl}$; C-reactive protein [CRP], $4.52 \mathrm{mg} / \mathrm{dl}$; ferritin, 17,968 $\mathrm{ng} / \mathrm{ml}$ ). This condition fulfilled the diagnostic criteria for disseminated intravascular coagulation (DIC) (9) and was strongly suggestive of hemophagocytic lymphohistiocytosis (HLH) (four of eight items met the Histiocyte Society HLH-2004 criteria, with highly elevated ferritin level) (10,11). Furthermore, the diagnostic criteria for 'very severe' SOS/VOD were met in accordance with the European Society for Blood and Marrow Transplantation diagnostic criteria for hepatic SOS/VOD in children (1). At this stage, we initiated the administration of rTM (380 U/kg/day) to control DIC on the basis of absent hemorrhagic diathesis and of prednisolone (PSL) $(1.8 \mathrm{mg} / \mathrm{kg} /$ day) to control HLH, with supportive therapies including blood transfusion; administration of ulinastatin, antithrombin III, and L-cysteine; and strengthened antibacterial therapy (to add amikacin sulfate).

His condition improved after the therapy, with defervescence and amelioration of abdominal pain. Levels of T-Bil, AST, ALT, and CRP improved after peaking at $2.7 \mathrm{mg} / \mathrm{dl}$, $1,963 \mathrm{U} / 1,1,292 \mathrm{U} / 1$, and $5.5 \mathrm{mg} / \mathrm{dl}$, respectively, on the subsequent day of rTM and PSL therapy. Furthermore, levels of coagulation markers and serum ferritin rapidly improved. The first abdominal Doppler ultrasonography performed at 2 days after rTM and PSL administration revealed bidirectional blood flow of the left portal vein. His body weight increased by $7 \%$ above the baseline value. Results of hepatitis virus panel were negative, and blood cultures were sterile. Liver biopsy for pathological confirmation was not performed in consideration of thrombocytopenia and coagulopathy. After day 7 of rTM therapy, the schedule for radio- and chemotherapy was restarted at 1 week later with the dose of vincristine in 
Table I. VAC-induced hepatopathy in rhabdomyosarcoma reviewed.

\begin{tabular}{|c|c|c|c|c|c|c|c|c|}
\hline $\begin{array}{l}\text { Age, } \\
\text { year }\end{array}$ & Sex & $\begin{array}{l}\text { Tumor } \\
\text { site }\end{array}$ & $\begin{array}{l}\text { Therapy for hepatotherapy } \\
\text { other than supportive care }^{\mathrm{a}}\end{array}$ & $\begin{array}{c}\text { Duration of } \\
\text { hepatotherapy }\end{array}$ & $\begin{array}{l}\text { Outcome of } \\
\text { hepatotherapy }\end{array}$ & $\begin{array}{l}\text { Further } \\
\text { therapy }\end{array}$ & $\begin{array}{l}\text { Outcome } \\
\text { of RMS }\end{array}$ & (Refs.) \\
\hline 0.3 & & & & & $\mathrm{R}$ & VIC/VTC & NED & (4) \\
\hline 1 & M & Thigh & Gabexate mesilate & 1 month & $\mathrm{R}$ & VAC & NED & (19) \\
\hline 1.1 & & & Defibrotide & & Dead & & Dead & $(4)$ \\
\hline 1.5 & & & & & $\mathrm{R}$ & VAC & NED & (4) \\
\hline 1.7 & & & & & $\mathrm{R}$ & Off & NED & (4) \\
\hline 1.7 & & & Ventilator & & Dead & & Dead & (4) \\
\hline 1.8 & & & & & $\mathrm{R}$ & VIE & NED & $(4)$ \\
\hline 1.8 & M & Face & High-dose methylprednisolone & 3-4 weeks & $\mathrm{R}$ & $\mathrm{VECb}$ & NED & $(22)$ \\
\hline 2 & M & Face & Abdominal paracentesis & 2 weeks & $\mathrm{R}$ & VIE & NED & $(21)$ \\
\hline 2.3 & & & Ventilator & & $\mathrm{R}$ & VTC/VIE & NED & $(4)$ \\
\hline 2.4 & & & & & $\mathrm{R}$ & Off & NED & (4) \\
\hline 2.7 & & & Ventilator & & $\mathrm{R}$ & VIE & NED & (4) \\
\hline 2.7 & & & & & $\mathrm{R}$ & VIE & NED & (4) \\
\hline 3.8 & & & & & $\mathrm{R}$ & VAC & NED & (4) \\
\hline 3.8 & $\mathrm{~F}$ & Head & $\begin{array}{l}\text { Thoracentesis, activated factor IX } \\
\text { concentrate, ventilator }\end{array}$ & $>1$ month & $\begin{array}{l}\text { Left } \\
\text { ptosis }\end{array}$ & VIE & NED & (17) \\
\hline 4.0 & & & Ventilator & & $\mathrm{R}$ & VIE & NED & (4) \\
\hline 4.7 & & & & & Dead & & Dead & (4) \\
\hline 5.0 & & & & & Dead & & Dead & (4) \\
\hline 6.1 & & & & & $\mathrm{R}$ & Off & NED & $(4)$ \\
\hline 9 & $\mathrm{~F}$ & Limb & $\begin{array}{l}\text { Defibrotide, abdominal paracentesis, } \\
\text { ventilator }\end{array}$ & & $\mathrm{R}$ & Off & NED & (23) \\
\hline 12.9 & & & & & $\mathrm{R}$ & VIE & Relapse & (4) \\
\hline 14.3 & & & & & $\mathrm{R}$ & VAC & NED & $(4)$ \\
\hline 15.5 & & $\begin{array}{l}\text { Para } \\
\text { testicular }\end{array}$ & rTM, PSL & 1 week & $\mathrm{R}$ & VAC & NED & $\begin{array}{l}\text { Index } \\
\text { case }\end{array}$ \\
\hline 17.9 & & & & & $\mathrm{R}$ & VAC & NED & \\
\hline
\end{tabular}

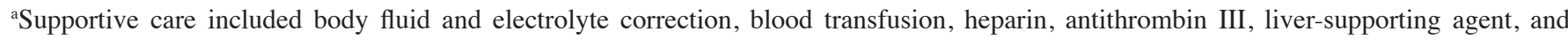
antibiotics. bE means epirubicin only here; other Es mean etoposide. RMS, rhabdomyosarcoma; M, male; F, female; V, vincristine; A, actinomycin D; C, cyclophosphamide; I, ifosfamide; E, etoposide; T, topotecan; G-CSF, granulocyte colony-stimulating factor; rTM, recombinant thrombomodulin; PSL, prednisolone; R, recover; NED, no evidence of disease.

full and actinomycin D in half. Although the patient had two episodes of isolated fever during vincristine administration, severe hepatopathy with inflammation and coagulopathy never recurred. PSL was started to be tapered and finished at 1 month later. He is alive and well on disease-free state of RMS at the age of 16 years and 6 months.

Serum concentrations of proinflammatory cytokines were measured using an established method by LSI Medience Corporation (Tokyo, Japan) with kits from R\&D Systems, Inc. (Minneapolis, MN, USA). The levels of tumor necrosis factor- $\alpha$ (TNF- $\alpha$ ) (QuantiGlo ELISA Human TNF- $\alpha$ Immunoassay with a lower detection limit of $0.55 \mathrm{pg} / \mathrm{ml}$ : Non-detectable [ND] to $9.03 \mathrm{pg} / \mathrm{ml}$ in healthy volunteers), interleukin-1 $\beta$ (IL-1 $\beta$ ) (Quantikine HS ELISA Human IL-1 $\beta / \mathrm{IL}-1 \mathrm{~F} 2$ Immunoassay with a lower detection limit of $0.125 \mathrm{pg} / \mathrm{ml}$ : ND to $0.606 \mathrm{pg} / \mathrm{ml}$ in healthy volunteers), and interleukin-6 (IL-6) (QuantiGlo ELISA Human IL-6 Immunoassay with a lower detection limit of $0.30 \mathrm{pg} / \mathrm{ml}$ : ND to $5.84 \mathrm{pg} / \mathrm{ml}$ in healthy volunteers) were as follows: $1.84,<0.125$, and $7.25 \mathrm{pg} / \mathrm{ml}$ at day 5 of the 13 th week (before the event); 2.82,0.458, and $363 \mathrm{pg} / \mathrm{ml}$ at day 3 of the 14th week (day of rTM and PSL therapy initiation before administration); and $1.76,<0.125$, and $46.8 \mathrm{pg} / \mathrm{ml}$ at day 5 of the 14 th week ( 2 days after rTM and PSL therapy initiation), respectively. The cytokine profile showed an increase with hepatopathy development and a decrease immediately after drug initiation.

\section{Discussion}

SOS/VOD is a life-threatening complication of anticancer drug administration that was originally identified as a transplant-related endothelial disease. In the liver, recruited monocytes/macrophages and resident Kupffer cells are thought to play important roles on the insulted sinusoidal walls $(12,13)$, with activated Kupffer cells having been confirmed to secrete IL-1 $\beta$, IL-6, and TNF- $\alpha$ (14-16).

Particularly in children, SOS/VOD can also occur as a complication of conventional radio- and chemotherapy outside of the transplant setting with recurrent association 
with actinomycin D, vincristine, cyclophosphamide, and 6-mercaptopurine (1). There was little recognition of the risk of VAC-induced hepatopathy among children with RMS until the case report of Kanwar et al (17). Subsequently, a clinical trial performed by the Intergroup Rhabdomyosarcoma Study Group reported an incidence rate of $5.3 \%$ (4). Table I shows hepatopathy in conventional chemotherapy regimen for RMS (2-4,18-22). Most cases were supportively managed mainly by conventional anticoagulation. Therapies targeting inflammation have scarcely been reported to date. One case was reported to be treated with high-dose methylprednisolone. Although the patient recovered, the condition continued to worsen up to 4 days after therapy initiation (22). Defibrotide, which protects the endothelial cells from continued damage due to cytotoxic drugs and TNF- $\alpha$, was shown to be a feasible therapeutic option for both transplant- and non-transplant-associated SOS/VOD (23). In a review, when defibrotide was administered in two patients, one died, whereas the other recovered after intensive care including ventilatory support $(4,23)$. Nonetheless, defibrotide is yet to be licensed for clinical use in Japan.

Our case indicated the marked hyperferritinemia, which was substantiated with hypercytokinemia, as severe inflammation. We used a combination of rTM and PSL, and all of the patient's symptoms and laboratory data, including proinflammatory cytokine profile, immediately improved after the administration of these drugs. rTM itself has been reported to have a unique anti-inflammatory property by binding to high-mobility group box 1 protein (HMGB1), which is secreted by activated monocytes and macrophages $(6,24)$. However, the effect of systemic corticosteroid treatment was observed to be confined to reduction in extracellular HMGB1 expression, but not in intracellular expression (25). Kurokohchi et al (26) reported that rTM-but not corticosteroid-for fulminant hepatic failure, which is also characterized by severe liver inflammation, was sufficiently effective. From the viewpoint of relatively long duration before withdrawal and various side effects, corticosteroid use is best avoided, if possible. In addition, although the in vitro anti-inflammatory effect of ulinastatin has been shown (27), its effect on liver inflammation in the clinical setting has not yet been reported.

We presume that rTM could ameliorate not only coagulopathy but also excessive inflammation via suppression of proinflammatory cytokines. As a novel treatment for VAC-associated hepatopathy with inflammatory profile, rTM could become promising for reducing treatment-related mortality and, more substantially, minimizing delays and dose reduction in chemotherapy for RMS.

\section{Acknowledgements}

Not applicable.

\section{Funding}

No funding was received.

\section{Availability of data and materials}

The datasets used and/or analyzed during the present study are available from the corresponding author on reasonable request.

\section{Authors' contributions}

TK analyzed the medical records of the patients, measured cytokine levels of the patient and was the principal writer primarily responsible for drafting the manuscript. MN, HN and RF were responsible for the clinical management of the patient with helpful discussion for the completion of the study. RF created the high-resolution figure. HN supervised the project. SO interpreted the data collected by TK, was involved in drafting the manuscript critically for important intellectual content and supervised the conduct of the present study.

\section{Ethics approval and consent to participate}

Not applicable.

\section{Patient consent for publication}

General consent for research including publication of the case report was obtained from the patient and his mother.

\section{Competing interests}

The authors declare that they have no competing interests.

\section{References}

1. Corbacioglu S, Carreras E, Ansari M, Balduzzi A, Cesaro S, Dalle JH, Dignan F, Gibson B, Guengoer T, Gruhn B, et al: Diagnosis and severity criteria for sinusoidal obstruction syndrome/veno-occlusive disease in pediatric patients: A new classification from the European society for blood and marrow transplantation. Bone Marrow Transplant 53: 138-145, 2018.

2. Ortega JA, Donaldson SS, Ivy SP, Pappo A and Maurer HM: Venoocclusive disease of the liver after chemotherapy with vincristine, actinomycin $\mathrm{D}$, and cyclophosphamide for the treatment of rhabdomyosarcoma. A report of the intergroup rhabdomyosarcoma study group. Childrens cancer group, the pediatric oncoloy group, and the pediatric intergroup statistical center. Cancer 79: 2435-2439, 1997.

3. Sulis ML, Bessmertny O, Granowetter L, Weiner M and Kelly KM: Veno-occlusive disease in pediatric patients receiving actinomycin D and vincristine only for the treatment of rhabdomyosarcoma. J Pediatr Hematol Oncol 26: 843-846, 2004.

4. Arndt C, Hawkins D, Anderson JR, Breitfeld P, Womer R and Meyer W: Age is a risk factor for chemotherapy-induced hepatopathy with vincristine, dactinomycin, and cyclophosphamide. J Clin Oncol 22: 1894-1901, 2004.

5. Saito H, Maruyama I, Shimazaki S, Yamamoto Y, Aikawa N, Ohno R, Hirayama A, Matsuda T, Asakura H, Nakashima M and Aoki N: Efficacy and safety of recombinant human soluble thrombomodulin (ART-123) in disseminated intravascular coagulation: Results of a phase III, randomized, double-blind clinical trial. J Thromb Haemost 5: 31-41, 2007.

6. Abeyama K, Stern DM, Ito Y, Kawahara K, Yoshimoto Y, Tanaka M, Uchimura T, Ida N, Yamazaki Y, Yamada S, et al: The $\mathrm{N}$-terminal domain of thrombomodulin sequesters high-mobility group-B1 protein, a novel anti-inflammatory mechanism. J Clin Invest 115: 1267-1274, 2005.

7. Loghmani $\mathrm{H}$ and Conway EM: Exploring traditional and nontraditional roles for thrombomodulin. Blood 132: 148-158, 2018

8. Walterhouse DO, Pappo AS, Meza JL, Breneman JC, Hayes-Jordan AA, Parham DM, Cripe TP, Anderson JR, Meyer WH and Hawkins DS: Shorter-duration therapy using vincristine, dactinomycin, and lower-dose cyclophosphamide with or without radiotherapy for patients with newly diagnosed low-risk rhabdomyosarcoma: A report from the soft tissue sarcoma committee of the children's oncology group. J Clin Oncol 32: 3547-3552, 2014. 
9. Wada H, Takahashi H, Uchiyama T, Eguchi Y, Okamoto K, Kawasugi K, Madoiwa S, Asakura H and Diagnostic and therapeutic guidelines for hemophagocytic lymphohistiocytosis: The approval of revised diagnostic criteria for DIC from the Japanese Society on thrombosis and hemostasis. Thromb J 15: 17, 2017.

10. Henter JI, Horne A, Aricó M, Egeler RM, Filipovich AH Imashuku S, Ladisch S, McClain K, Webb D, Winiarski J and Janka G: HLH-2004: Diagnostic and therapeutic guidelines for hemophagocytic lymphohistiocytosis. Pediatr Blood Cancer 48: 124-131, 2007.

11. Allen CE, Yu X, Kozinetz CA and McClain KL: Highly elevated ferritin levels and the diagnosis of hemophagocytic lymphohistiocytosis. Pediatr Blood Cancer 50: 1227-1235, 2008.

12. DeLeve LD, Shulman HM and McDonald GB: Toxic injury to hepatic sinusoids: Sinusoidal obstruction syndrome (veno-occlusive disease). Semin Liver Dis 22: 27-42, 2002.

13. DeLeve LD, Ito Y, Bethea NW, McCuskey MK, Wang X and McCuskey RS: Embolization by sinusoidal lining cells obstructs the microcirculation in rat sinusoidal obstruction syndrome. Am J Physiol Gastrointest Liver Physiol 284: G1045-G1052, 2003.

14. Szabo G and Petrasek J: Inflammasome activation and function in liver disease. Nat Rev Gastroenterol Hepatol 12: 387-400, 2015.

15. Schmidt-Arras D and Rose-John S: IL-6 pathway in the liver: From physiopathology to therapy. J Hepatol 64: 1403-1415, 2016.

16. Sato K, Hall C, Glaser S, Francis H, Meng F and Alpini G Pathogenesis of kupffer cells in cholestatic liver injury. Am J Pathol 186: 2238-2247, 2016.

17. Kanwar VS, Albuquerque ML, Ribeiro RC, Kauffman WM and Furman WL: Veno-occlusive disease of the liver after chemotherapy for rhabdomyosarcoma: Case report with a review of the literature. Med Pediatr Oncol 24: 334-340, 1995.

18. Adachi $\mathrm{N}$ and Matsuda I: Veno-occlusive disease of the liver after combined adjuvant chemotherapy for a 1-year-old boy with rhabdomyosarcoma: Potential usefulness of the gabexate mesylate (FOY). J Pediatr Gastroenterol Nutr 14: 314-318, 1992.

19. D'Antiga L, Baker A, Pritchard J, Pryor D and Mieli-Vergani G: Veno-occlusive disease with multi-organ involvement following actinomycin-D. Eur J Cancer 37: 1141-1148, 2001.
20. Cecen E, Uysal KM, Ozguven A, Gunes D, Irken G and Olgun N: Veno-occlusive disease in a child with rhabdomyosarcoma after conventional chemotherapy: Report of a case and review of the literature. Pediatr Hematol Oncol 24: 615-621, 2007.

21. Chen IL, Yang SN, Hsiao CC, Wu KS and Sheen JM: Treatment with high-dose methylprednisolone for hepatic veno-occlusive disease in a child with rhabdomyosarcoma. Pediatr Neonatol 49: 141-144, 2008.

22. Choi A, Kang YK, Lim S, Kim DH, Lim JS and Lee JA: Severe hepatic sinusoidal obstruction syndrome in a child receiving vincristine, actinomycin-D, and cyclophosphamide for rhabdomyosarcoma: Successful treatment with defibrotide. Cancer Res Treat 48: 1443-1447, 2016.

23. Kernan NA, Richardson PG, Smith AR, Triplett BM, Antin JH, Lehmann L, Messinger Y, Liang W, Hume R, Tappe W, et al: Defibrotide for the treatment of hepatic veno-occlusive disease/sinusoidal obstruction syndrome following nontransplant-associated chemotherapy: Final results from a post hoc analysis of data from an expanded-access program. Pediatr Blood Cancer 65: e27269, 2018.

24. Scaffidi P, Misteli T and Bianchi ME: Release of chromatin protein HMGB1 by necrotic cells triggers inflammation. Nature 418: 191-195, 2002.

25. Ulfgren AK, Grundtman C, Borg K, Alexanderson $\mathrm{H}$, Andersson U, Harris HE and Lundberg IE: Down-regulation of the aberrant expression of the inflammation mediator high mobility group box chromosomal protein 1 in muscle tissue of patients with polymyositis and dermatomyositis treated with corticosteroids. Arthritis Rheum 50: 1586-1594, 2004.

26. Kurokohchi K, Imataki O and Kubo F: Anti-inflammatory effect of recombinant thrombomodulin for fulminant hepatic failure. World J Gastroenterol 21: 8203-8207, 2015.

27. Wei F, Liu S, Luo L, Gu N, Zeng Y, Chen X, Xu S and Zhang D: Anti-inflammatory mechanism of ulinastatin: Inhibiting the hyperpermeability of vascular endothelial cells induced by TNF- $\alpha$ via the RhoA/ROCK signal pathway. Int Immunopharmacol 46: 220-227, 2017. 